\title{
Requirements for GNEP Transmutation Fuels
}

\author{
D. C. Crawford \\ M. K. Meyer \\ S. L. Hayes
}

March 2007

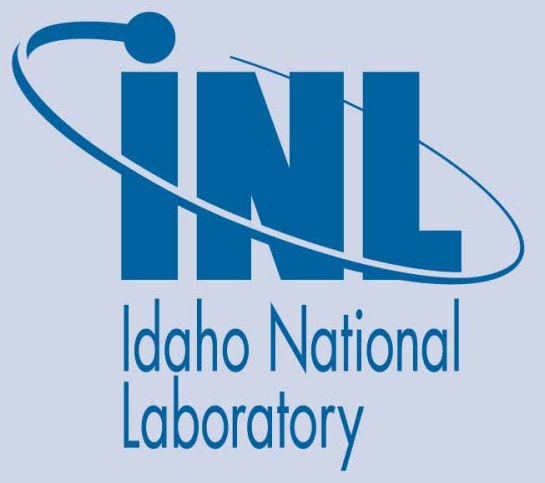

The INL is a U.S. Department of Energy National Laboratory operated by Battelle Energy Alliance 
INL/EXT-07-12468

\section{Requirements for GNEP Transmutation Fuels}

D. C. Crawford

M. K. Meyer

S. L. Hayes

March 2007

\section{Idaho National Laboratory \\ Idaho Falls, Idaho 83415}

Prepared for the

U.S. Department of Energy

Office of Nuclear Energy

Under DOE Idaho Operations Office

Contract DE-AC07-05ID14517 


\subsection{Introduction}

The purpose of this document is to provide a baseline set of requirements to guide fuel fabrication development and irradiation testing performed as part of the AFCRD Transmutation Fuel Development Program. This document can be considered a supplement to the GNEP TRU Fuel Development and Qualification Plan, and will be

revised as necessary to maintain a documented set of fuel testing objectives and requirements consistent with programmatic decisions and advances in technical knowledge.

As a part of the AFCRD (Advanced Fuel Cycle Research and Development) program supporting implementation of the GNEP (Global Nuclear Energy Partnership) program, the objective of the transmutation fuel development effort is to develop fuel technology(s) for the efficient destruction of transuranic nuclides produced during irradiation of uranium-based fuel in power producing nuclear reactors. The motivation for transmutation is to optimize the ability of the U.S. and its partner fuel cycle states to manage the used fuel generated by the GNEP enterprise. It is expected that the technology developed will also be used to manage the current U.S. light water reactor spent fuel inventory.

The GNEP strategy uses fast-spectrum reactors to transmute and fission all neptunium, plutonium, americium, and possibly curium isotopes. The success of this technology will depend on several technology advances, including the development of a robust fuel system that is a component of an economically viable transmutation system. The performance of fuels with high minor actinide content has not been proven, and requires considerable proof of concept testing prior to qualification.

At this time, many of the details of the fast-spectrum transmutation reactor and associated transmutation scheme are not well defined. Global conversion ratios ranging from 0.25 to 0.75 are under consideration, and fuel operating conditions during normal and offnormal operation are not yet known. The output streams from the separations processes under consideration are not sufficiently characterized to provide data to develop a TRU feedstock specification. Likewise, fuel physical and operating parameters have not been set, including the dimensions of fuel rods and makeup of subassembly bundles.

After the system has been completely defined, there will still be some inherent variability in actinide material feed streams due to the wide range of fuel burnups and cooling times represented in the current inventory of irradiated LWR fuel, in addition to the inherent change in composition as the system approaches equilibrium. Both metallic and oxide fuel forms are presently considered to be candidates for transmutation fuel. These considerations necessitate the testing of a wide range of fuel compositions under a broad range of irradiation testing conditions, and only a correspondingly broad set of fuel requirements can currently be defined. 


\subsection{Assumptions}

- The transmutation system will be a sodium-cooled fast-spectrum reactor, operating under conditions similar to previous and currently operating power and test reactors.

- The conversion ratio of the reactor will be in the range of $0.25-0.75$.

- The fuel will be clad in stainless steel alloy

- The fuel will be either sodium-bonded metallic fuel or helium-bonded oxide fuel

- The fuel will contain elemental mixtures of uranium, plutonium, neptunium, americium, and curium

- The separations process may result in carryover of fission products which will be incorporated into the recycled fuel

\subsection{Fuel functions}

Transmutation fuel rods and assemblies shall perform the following functions:

- Position the materials to be transmuted into the neutron flux of the transmutation reactor

- Provide for efficient heat removal for economic energy production

- Provide a barrier to the release of fission products to the coolant

- Provide a convenient unit for insertion of fresh fuel into the core and for removal, handling and processing of spent fuel

\subsection{Fuel requirements}

Because the design specifics of the proposed fast spectrum transmutation reactor are not specified, only general requirements can currently be formulated based on design studies and past fast reactor operating experience. These requirements are listed in this section.

\subsection{Fuel dimensional requirements}

The fuel rod cladding outer diameter will be in the range of $0.58 \mathrm{~cm}$ to $0.76 \mathrm{~cm}(0.23-$ 0.30 in.). 


\subsection{Composition}

4.2.1 Actinide content The major consideration that impacts transmutation fuel composition is the desired transmutation rate. Low conversion ratio designs $(\mathrm{CR}=0.25)$ are more highly loaded with TRU and contain less U-238 than higher conversion ratio designs. The table below provides approximate fuel composition ranges corresponding to the currently considered range of conversion ratios.

\begin{tabular}{|r|c|}
\hline Element - isotope & Range (wt.\%) in fuel \\
\hline Uranium (238) & $40-60$ \\
\hline $\begin{array}{r}\mathrm{Pu} \text { (sum of all } \\
\text { isotopes) }\end{array}$ & $20-30$ \\
\hline Am-241 & $3-7$ \\
\hline $\mathrm{Np}-237$ & $2-4$ \\
\hline $\mathrm{Cm}-244$ & $0-1$ \\
\hline $\mathrm{Zr}$ & $10-20$ \\
\hline RE fission products & $0-1.5$ \\
\hline
\end{tabular}

4.2.2 Fission product content The fuel recycle processes, specifically pyro-processing, under consideration in the U.S. will provide recycled fuel feed that contains some residual fission products. The amounts of fission products that must be accommodated in the recycle fuel remain to be determined through separations R\&D. For the purposes of this document, it will be assumed that rare earth fission product carryover is limited to 5 wt. $\%$ or less of the transuranic metal mass.

\subsection{Nominal fuel operating conditions}

4.3.1 Fuel rod linear power: $30-45 \mathrm{~kW} / \mathrm{m}$ : This value is typical of sodium cooled fast reactors.

4.3.2 Cladding temperature: $550^{\circ} \mathrm{C}$ : Peak cladding temperature will be approximately $550^{\circ} \mathrm{C}$, based on operating histories from typical fast reactors.

\subsection{Burnup and exposure limits}

4.4.1 Burnup: 30 at.\%: For a well-developed fuel with a well-established fabrication process, breach probability and consequences are in large part correlated with burnup. Burnup limits are typically established to ensure that breach probability and consequences are acceptable. Maximum burnup capability is desired for the transmutation mission in order to reduce the number of recycles required to completely transmute a given quantity of material, because some amount of TRU will be lost to secondary waste streams during each recycle and refabrication pass. 30 at.\% heavy metal 
burnup is an aggressive target for conventional fuel, but may be reached by optimizing fuel design parameters.

4.4.2 Fuel pin internal pressurization limit: $12.6 \mathrm{MPa}$ (1800 psi): This value is based on EBR-II operating experience with 316 and HT-9 cladding and is a nominal value chosen to provide a baseline for design of fuel specimens for testing.

4.4.3 Neutron exposure: $4 \times 10^{23} \mathrm{n} / \mathrm{cm}^{2}(\mathrm{E}>0.1 \mathrm{MeV})$ : Fuel assembly burnup for previous fast reactor designs was initially limited by the performance of the fuel itself, but later was limited by the neutron fluence that could be tolerated by the fuel cladding or fuel assembly ducts due irradiation-induced dimensional changes. Burnup of the most recent driver fuels for the EBR-II and the Fast Flux Test Facility (FFTF) was limited by duct dilations and distortions rather than by failure of the fuel rods. HT-9 clad MOX fuel with HT-9 ducts in the FFTF attained fluences of $3.9 \times 10^{23} \mathrm{n} / \mathrm{cm}^{2}$ with no observed performance concerns. (See [1] or [3]) Because HT-9 is proposed as a reference cladding and duct material for transmutation, a limit of $4 \times 10^{23} \mathrm{n} / \mathrm{cm}^{2}(\mathrm{E}>0.1 \mathrm{MeV})$ is proposed.

\subsection{Fuel performance during normal service conditions}

Requirements for irradiation performance are based on safety, economics, and operability considerations and are established for normal and off-normal conditions. Normal conditions are those encountered in the reactor during steady-state operation and during operational transients (e.g., during startup and shutdown).

4.5.1 Fuel rod breach rate: $3.3 \times 10^{-4}$ : In general, release of radionuclides from fuel rods into coolant is undesirable from perspectives of system operability and safety. Some small number of fuel breaches can typically be tolerated without unacceptable exposure of workers to radiation from radionuclides in the coolant system. Experience with Experimental Breeder Reactor II (EBR-II) metallic fuel had determined that a breach rate of $3.3 \times 10^{-4}$ (less then one pin per EBR-II core loading) with 2-sigma confidence would be acceptable, and that rate is proposed as an initial baseline for transmutation fuel.

\subsection{Fuel performance during off-normal and accident conditions}

Off-normal conditions are those encountered during anticipated and unlikely events, which will be determined through the reactor design evaluation process and analyzed during safety evaluation for licensing.

In general, safety requirements for the fuel will ensure that these components accomplish the following system safety objectives:

- Provide operators with the ability to control the extent of the nuclear chain reaction 
- Contain hazardous radionuclides to prevent exposure of workers or the public, except as deemed acceptable by definition of design-basis accidents

Specific safety objectives for fuel can then be defined as the following:

- Maintain fissionable materials in a known and predictable configuration at all times

- Maintain a coolable geometry at all times

- Provide the first barrier against radionuclide release except under design-basis accident conditions for which release through the first barrier would be acceptable.

As accidents are defined for the transmutation reactor, the evaluation of potential consequences will identify specific requirements to ensure that consequences are acceptable for postulated accidents. Examples of Design-Basis Accidents that will need to be addressed include reactivity-insertion accidents leading to transient overpower (TOP) conditions and (LOF) events that arise when an initiating event disrupts the normal flow of coolant into the core or into a fuel assembly.

TOP conditions typically involve higher-than-normal fission rates, which would induce higher-than-normal fuel temperatures and associated cladding and coolant temperature increases. Determination of fuel performance during these events requires that 1) the event be defined to bound a class of reactors or a specific reactor design, and 2) that transient tests be conducted to determine fuel behavior during the defined event. Requirements driven by TOP might include minimum temperature margin to fuel melting, minimum temperature margin to fuel-cladding eutectic formation, or a limit to fuel or fission products released into coolant channels.

LOF events typically result in increased cladding temperatures but have less impact on fuel temperatures than do TOP events, because they are usually followed by a SCRAM. Phenomena that can lead to fuel failure during such events include increased fuel rod pressurization, stress rupture of softened cladding, and accelerated cladding wastage due to increased diffusion of fuel constituents or fission products into cladding. Safety requirements that address such concerns might include a cladding cumulative damage limit or fuel rod pressure limit.

\subsection{Fabrication and recycle process requirements}

4.7.1 Compatible with recycle technology. The ability of the transmutation system to perform its mission will be strongly dependent on the performance of the recycle technology. Therefore, the selected fuel design and the selected recycle technology must be mutually compatible. The selection and optimization of these technologies will be based on considerations of economics, facility and fuel reliability, and waste management.

4.7.2 Fabrication considerations. The presence of residual fission products and actinides that emit high radiation fields will require that fuel fabrication be performed using 
shielded equipment and/or operating spaces. Radioactive contamination on the surface of the fabrication equipment and in the fabrication spaces will be high, preventing hands-on maintenance of the equipment. Therefore, fuel fabrication processes must be amenable to remote application, and the equipment amenable to remote operation and maintenance using remote manipulators.

4.7.3 Fabrication losses of TRU constituents to secondary waste: $<1 \%$ per recycle pass. The success of the transmutation system will require that only small amount of transuranic elements be discharged through secondary waste disposal. This implies that such losses due to adherence to fuel fabrication molds, dies, crucibles, etc. must be limited. Other such losses will necessarily be incurred with the recycle process. Fuel fabrication-related losses of transuranic elements will initially be limited to $1 \%$ of the processed TRU mass per recycle pass, with the objective of reducing these requirements to $<0.1 \%$.

\subsection{References}

1. R. D. Leggett and L. C. Walters, J. of Nucl. Mater., 204 (1993) 23-32.

2. B. R. Seidel, L. C. Walters, and Y. I. Chang, J. of Metals, v. 39. No. 4 (1987) 10-13.

3. Baker, Bard, Leggett, and Pitner, J. Nucl. Mater., 204 (1993) 109-118. 